\title{
Fiber Fabry-Perot Interferometer for Curvature Sensing
}

\author{
Catarina S. MONTEIRO ${ }^{1,2^{*}}$, Marta S. FERREIRA ${ }^{1,2}$, Susana O. SILVA ${ }^{1,2}$, \\ Jens KOBELKE ${ }^{3}$, Kay SCHUSTER ${ }^{3}$, Jörg BIERLICH ${ }^{3}$, and Orlando FRAZÃO ${ }^{1,2}$ \\ ${ }^{1}$ Department of Physics and Astronomy, Sciences Faculty, Porto University, Rua do Campo Alegre 687, 4169-007 Porto, \\ Portugal \\ ${ }^{2}$ INESC-TEC, Rua do Campo Alegre 687, 4169-007 Porto, Portugal \\ ${ }^{3}$ IPHT Jena - Leibniz Institute of Photonic Technology, Albert-Einstein-Str. 9, 07745 Jena, Germany \\ "Corresponding author: Catarina S. MONTEIRO E-mail: catarina.s.monteiro@inesctec.pt
}

\begin{abstract}
A curvature sensor based on an Fabry-Perot (FP) interferometer was proposed. A capillary silica tube was fusion spliced between two single mode fibers, producing an FP cavity. Two FP sensors with different cavity lengths were developed and subjected to curvature and temperature. The FP sensor with longer cavity showed three distinct operating regions for the curvature measurement. Namely, a linear response was shown for an intermediate curvature radius range, presenting a maximum sensitivity of $68.52 \mathrm{pm} / \mathrm{m}^{-1}$. When subjected to temperature, the sensing head produced a similar response for different curvature radii, with a sensitivity varying from $0.84 \mathrm{pm} /{ }^{\circ} \mathrm{C}$ to $0.89 \mathrm{pm} /{ }^{\circ} \mathrm{C}$, which resulted in a small cross-sensitivity to temperature when the FP sensor was subjected to curvature. The FP cavity with shorter length presented low sensitivity to curvature.
\end{abstract}

Keywords: Curvature measurement; Fabry-Perot interferometer; optical fiber sensor

Citation: Catarina S. MONTEIRO, Marta S. FERREIRA, Susana O. SILVA, Jens KOBELKE, Kay SCHUSTER, Jörg BIERLICH, et al., "Fiber Fabry-Perot Interferometer for Curvature Sensing," Photonic Sensors, 2016, 6(4): 339-344.

\section{Introduction}

Optical fiber sensors based on Fabry-Perot (FP) cavities are an interesting solution for engineering applications. Due to the small dimensions, they can be easily embedded in more advanced structures. The first FP cavities were fabricated in 1993, by splicing two standard single mode fibers (SMFs) with a silica capillary tube and tested for the measurement of dynamic strain [1]. Over the last decades, this type of interferometric sensor has been used for sensing a wide range of physical parameters such as temperature, vibration, pressure, and refractive index [2-5]. A temperature sensor was proposed consisting of a tip of a single mode fiber coated with a thin film of polyvinyl alcohol [2]. The sensor provided a stable solution for temperature measurements, presenting a maximum sensitivity of $173.5 \mathrm{pm} /{ }^{\circ} \mathrm{C}$ above $80^{\circ} \mathrm{C}$. An all-fiber sensor based on FP interferometry was proposed for vibration measurements, showing insensitivity to environmental effects, along with the possibility of being embedded in composite material and used in harsh environments [3]. Refractive index was a key parameter for sensing purposes, and an FP-based sensing head formed by an air cavity was demonstrated [4]. In this case, the refractive index of gases was monitored as a function of pressure. An FP cavity based on a diaphragm-free hollow core silica tube was proposed [5]. The sensor head,

Received: 18 April 2016 / Revised: 8 June 2016

(C) The Author(s) 2016. This article is published with open access at Springerlink.com

DOI: $10.1007 / \mathrm{s} 13320-016-0333-9$

Article type: Regular 
composed by a hollow core silica tube spliced to a single mode fiber, was tested for pressure, refractive index, and temperature changes. The proposed sensor head was an interesting solution for both pressure and refractive index variations on fluids.

The optical fiber provides a great solution for curvature measurement purposes due to lightweight, compact dimensions, immunity to electromagnetic interference, and the resistance to corrosion. A curvature sensor based on a photonic crystal fiber was reported [6], showing a great sensitivity to the measurand and negligible sensitivity to temperature. Recently, a highly sensitive curvature sensor based on abrupt tapered fiber joined with a micro FP interferometer was presented [7]. The sensor head was sensitive only in visibility since the bending was applied before the FP cavity, not affecting the optical path length. Optical fiber sensors for curvature sensing were already tested for medical purposes [8], where an optical sensor was used to sense the radius of curvature of a rotary endodontic file inside an artificial tooth root canal.

In this work, an FP cavity for curvature sensing was proposed. The sensor was produced by fusion splicing a capillary silica tube between two SMFs. The capillary tube had an outer diameter similar to the one of the single mode fiber and an inner diameter of $60 \mu \mathrm{m}$. Two FP sensors with different cavity lengths were tested in curvature and temperature and characterized in visibility and wavelength shift. Finally, the cross-sensitivity for both measurands was also analyzed.

\section{Experimental results}

The experimental setup, shown in Fig. 1, is constituted by a broadband optical source, centered at $1550 \mathrm{~nm}$ and with a bandwidth of $100 \mathrm{~nm}$, an optical circulator and an optical spectrum analyzer (OSA). The circulator provides interrogation of the sensing head in reflection and the OSA reads the spectral response of the sensing head with a resolution of $0.1 \mathrm{~nm}$.

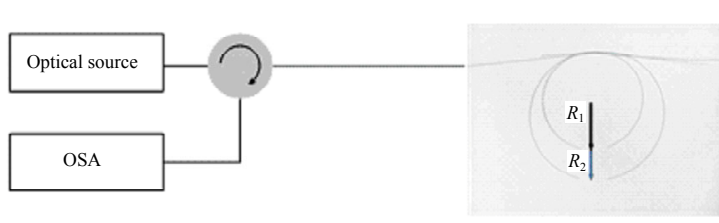

Fig. 1 Experimental setup, with photograph of the curvature sensor with different curvature radii.

Two FP cavities with different lengths were characterized. The first sensing head had a cavity length of $1140 \mu \mathrm{m}$ and was called an FP-Long sensor, whereas the second one had a cavity length of $500 \mu \mathrm{m}$ and is called FP-Short sensor. Both cavities were produced using a hollow core silica tube with an inner diameter of $\sim 60 \mu \mathrm{m}$, spliced between two SMFs. The arc discharge was performed with a splice machine in manual operation, where an offset of the capillary tube was applied to prevent its collapse. In Fig. 2, a scheme of the sensors used and a microscope photograph of the hollow core silica tube cross-section are presented.

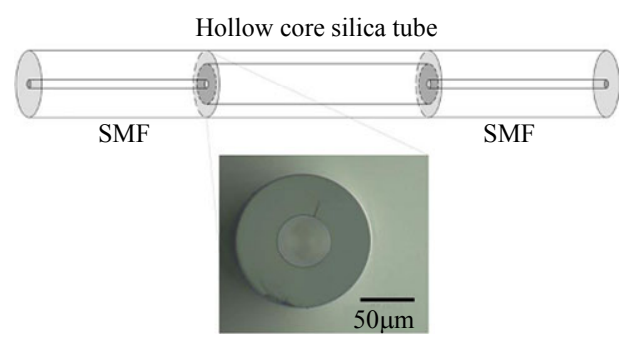

Fig. 2 Scheme of the sensor heads and a microscope image of the hollow core silica tube cross-section.

The spectrum of the two sensor heads used is shown in Fig. 3. The FP-Long sensor presented a visibility of 0.47 and had a free spectral range $(\Delta \lambda)$ of $1.04 \mathrm{~nm}$. Regarding the FP-Short sensor, it had a visibility of 0.41 and a free spectral range of $2.40 \mathrm{~nm}$. The light that was transmitted to the capillary tube traveled mostly through the hollow core, which was filled with air. Refractive index of the optical cavity can be estimated using (1), where $n$ is the refractive index and $L$ the cavity length [9].

$$
n=\frac{\lambda^{2}}{2 L \Delta \lambda}
$$

Using a central operation wavelength $\lambda$ of $1550 \mathrm{~nm}$, refractive indices $n$ of 1.0002 and 1.0009 
were calculated for FP-Long and FP-Short, respectively. Refractive index for both sensing heads was close to the value for air, which went according to the expected. The difference between obtained results and theoretical value of refractive index of air can be explained by possible errors committed while determining the cavity length due to software limitations.

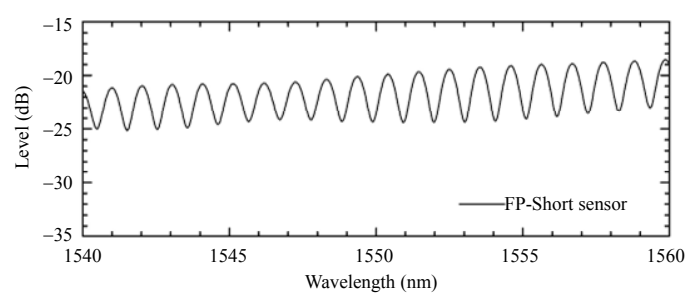

(a)

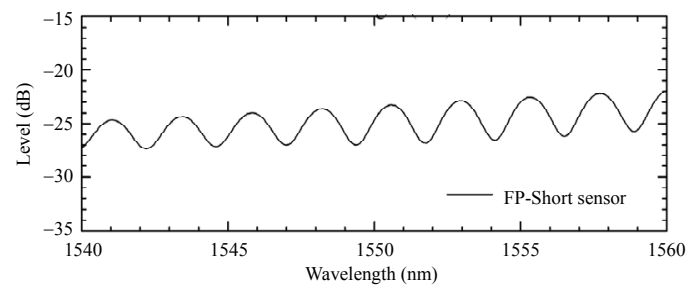

(b)

Fig. 3 Reflection spectrum of (a) FP-Long and (b) FP-Short without curvature applied.

A curvature study was carried out using an overhand knot configuration, as depicted in Fig. 1. The position of the sensor head was maintained parallel to the position of the knot. A variation on the relative position of the sensing head produced a variation in visibility, while maintaining the position of the fringes of the spectrum. Figure 4(a) shows the spectral behavior of the FP-Long when submitted to curvature. By stretching the fiber ends, the curvature radius diminished, resulting in the change in both visibility and wavelength as presented in Fig. 4(a). The curvature radius was maintained large enough to ensure that the losses were reduced. The visibility of the sensor head decreased $20 \%$ because the reduction of the curvature radius diminished the coupling efficiency of the FP mirrors, while the wavelength shift was due to the variation of the optical cavity length. In the case of FP-Short, even though the wavelength shift was negligible, visibility decreased when curvature increased as depicted in Fig. 4(b). The visibility diminished 10\% in the range of curvature studied, which was half of the value achieved in the FP-Long sensor.
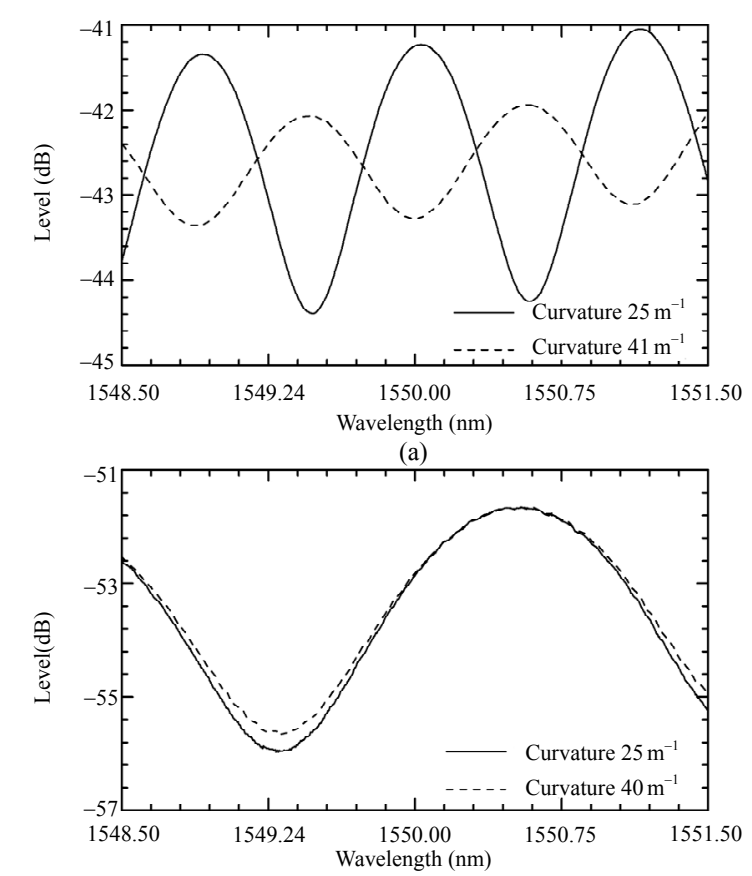

(b)

Fig. 4 Optical reflective spectrum for different curvature radius of (a) FP-Long and (b) FP-Short sensor.

Figure 5 shows the wavelength response of both sensing heads for different applied curvatures. The longer cavity, FP-Long, presented a non-linear response, but it was reasonable to divide the curvature range in three sub-regions where the response was linear. A sensitivity of $21.56 \pm$ $0.68 \mathrm{pm} / \mathrm{m}^{-1}$ was obtained for a high curvature radius, in the range of $45 \mathrm{~m}^{-1}$ to $55 \mathrm{~m}^{-1}$. In the case of a lower curvature radius, between $25 \mathrm{~m}^{-1}$ and $35 \mathrm{~m}^{-1}$, a sensitivity of $17.27 \pm 0.85 \mathrm{pm} / \mathrm{m}^{-1}$ was attained. A maximum sensitivity of $68.52 \pm$ $1.65 \mathrm{pm} / \mathrm{m}^{-1}$ was achieved for a curvature radius comprised between $35 \mathrm{~m}^{-1}$ and $45 \mathrm{~m}^{-1}$.

The different regions of curvature response can be explained by the material behavior to the curvature applied. In the region of $25 \mathrm{~m}^{-1}$ to $35 \mathrm{~m}^{-1}$, the curvature radius applied to the sensor was not enough to curve the silica tube. Over this region, the spectral variation was due to compression over the 
interfaces caused by bending. On the other hand, over the region of $45 \mathrm{~m}^{-1}$ to $55 \mathrm{~m}^{-1}$ the bend reached a saturation point at which the silica tube stopped bending. For higher curvature radius, the sensing head broke at the splicing points.

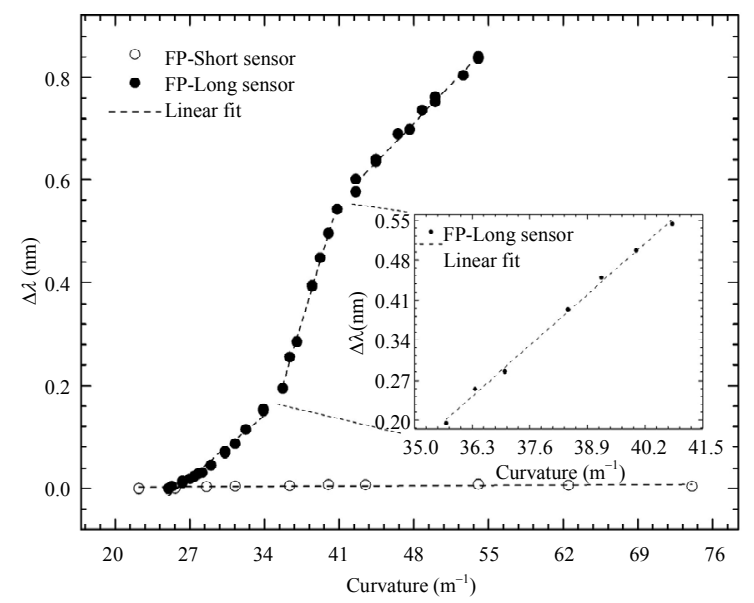

Fig. 5 Curvature response of FP-Long and FP-Short (inset: detail of the curvature response of FP-Long over the region of $35 \mathrm{~m}^{-1}$ to $45 \mathrm{~m}^{-1}$ ).

Table 1 summarizes the curvature sensitivities for the considered ranges. Curvature was also applied to FP-Short using the knot method, resulting in a negligible sensitivity to curvature, as observed in Fig. 5, with a corresponding sensitivity of $0.09 \mathrm{pm} / \mathrm{m}^{-1}$. The result was somehow expected, since the geometry of the FP-Short sensor was unchanged when curvature was applied, due to its small size. This implied that the optical path was independent of curvature changes.

Table 1 Sensitivity for curvature of FP-Long sensor.

\begin{tabular}{ccc}
\hline $\begin{array}{c}\text { Cavity length } \\
(\mu \mathrm{m})\end{array}$ & $\begin{array}{c}\text { Range of measurement } \\
\left(\mathrm{m}^{-1}\right)\end{array}$ & $\begin{array}{c}\text { Sensitivity } \\
\left(\mathrm{pm} /{ }^{\circ} \mathrm{C}\right)\end{array}$ \\
\hline \multirow{2}{*}{1140} & $25-35$ & 17.27 \\
& $35-45$ & 68.52 \\
& $45-55$ & 21.56 \\
\hline
\end{tabular}

Temperature responses of both sensing heads were also studied. Each sensor was placed in an oven, where temperature varied from $30^{\circ} \mathrm{C}$ to $80^{\circ} \mathrm{C}$, with a resolution of $0.1{ }^{\circ} \mathrm{C}$. The FP-Long was characterized in temperature considering two different curvatures, namely, $23.5 \mathrm{~m}^{-1}$ and $50 \mathrm{~m}^{-1}$, as presented in Fig. 6(a). The small wavelength change for the two different curvatures confirms the low sensitivity of the sensor to temperature, with sensitivities of $0.84 \mathrm{pm} /{ }^{\circ} \mathrm{C}$ and $0.89 \mathrm{pm} /{ }^{\circ} \mathrm{C}$, for $23.5 \mathrm{~m}^{-1}$ and $50 \mathrm{~m}^{-1}$ curvature radii, respectively.
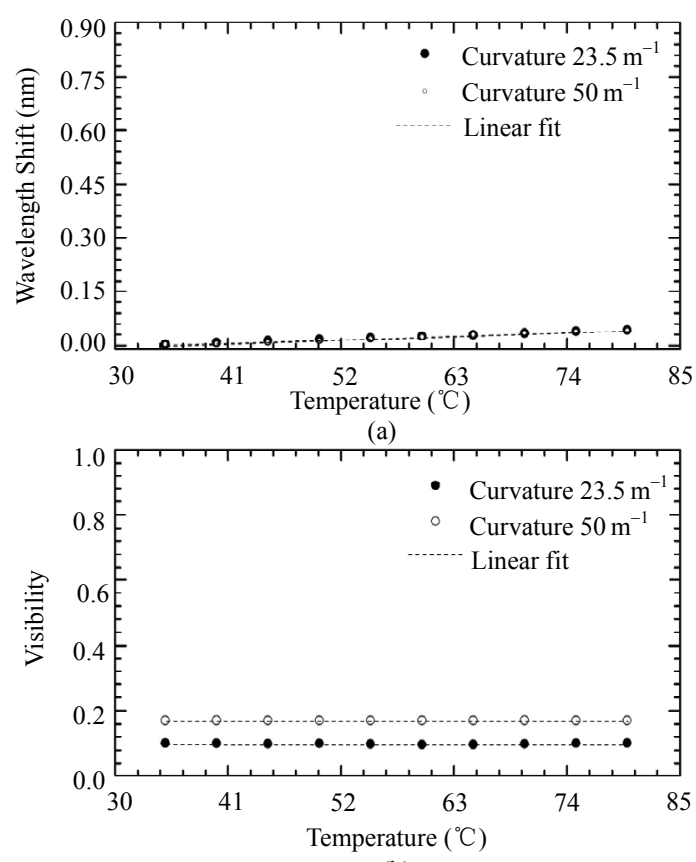

(b)

Fig. 6 Temperature characterization for FP-Long submitted to $23.5 \mathrm{~m}^{-1}$ and $50 \mathrm{~m}^{-1}$ of curvature applied (a) in wavelength and (b) in visibility.

The FP-Short was also tested without any curvature applied, presenting a sensitivity of $0.83 \mathrm{pm} /{ }^{\circ} \mathrm{C}$, as shown in Fig. 7(a). Since the sensor head was only constituted by pure silica, thermal expansion of the capillary tube was the main behavior for the low temperature sensitivity. When compared with an ultra-long capillary tube $(40 \mathrm{~mm}$ length) the temperature sensitivity was $20.6 \mathrm{pm} /{ }^{\circ} \mathrm{C}$ [10]. The cross-sensitivity between curvature and temperature was also determined for the FP-Long sensor. Results of $0.052 \mathrm{~m}^{-1} /{ }^{\circ} \mathrm{C}$ and $0.041 \mathrm{~m}^{-1} /{ }^{\circ} \mathrm{C}$ for the lower curvature radius of $25 \mathrm{~m}^{-1}$ to $35 \mathrm{~m}^{-1}$ and higher curvature radius of $45 \mathrm{~m}^{-1}$ to $55 \mathrm{~m}^{-1}$, respectively, were achieved. In the range of higher sensitivity to curvature a cross-sensitivity of $0.013 \mathrm{~m}^{-1} /{ }^{\circ} \mathrm{C}$ was also attained. For both sensor heads, visibility was almost constant throughout temperature variations, as depicted in Figs. 6(b) and 7(b). 

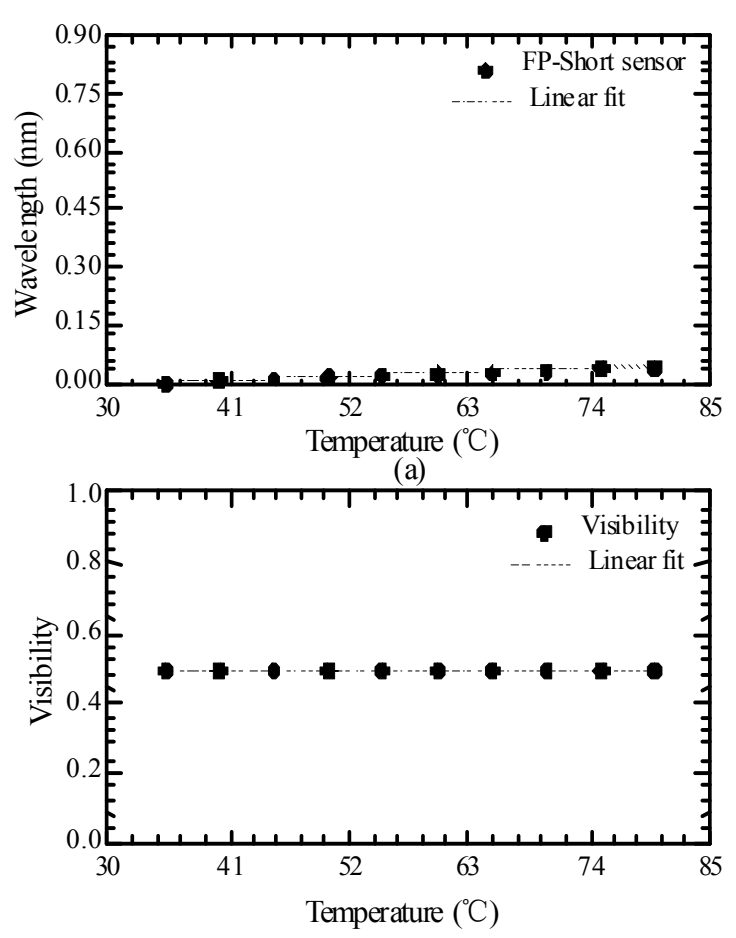

(b)

Fig. 7 Temperature characterization for FP-Short sensor not submitted to curvature (a) in wavelength and (b) in visibility.

\section{Conclusions}

A curvature sensor based on an Fabry-Perot interferometer was demonstrated. Curvature and temperature responses were compared for two different cavity lengths. The sensing head with a longer cavity length (FP-Long) showed a non-linear response to curvature, presenting a sensitivity of $21.56 \mathrm{pm} / \mathrm{m}^{-1}$ at the low curvature region of $25 \mathrm{~m}^{-1}$ to $35 \mathrm{~m}^{-1}$, and $17.27 \mathrm{pm} / \mathrm{m}^{-1}$ at the curvature range of $45 \mathrm{~m}^{-1}$ to $55 \mathrm{~m}^{-1}$. The FP-Long sensor presented a maximum curvature sensitivity of $68.52 \mathrm{pm} / \mathrm{m}^{-1}$, in the range of $35 \mathrm{~m}^{-1}$ to $45 \mathrm{~m}^{-1}$. For the FP-Long sensing head, the temperature response was studied, considering two different curvature radii, which led to the conclusion that curvature had a low influence on the temperature response. Besides, the longer cavity exhibited negligible sensitivity to temperature, presenting a maximum cross-sensitivity of $0.052 \mathrm{~m}^{-1} /{ }^{\circ} \mathrm{C}$. The smallest cavity (FP-Short) showed low sensitivity to the parameters studied, providing an alternative solution to measure others physical parameters. The proposed configuration can be easily adapted in pipeline with curvature radii between $0.04 \mathrm{~m}(1.58$ inches $)$ and $0.02 \mathrm{~m}$ (0.79 inches).

\section{Acknowledgment}

Project NORTE-01-0145-FEDER-000036 is financed by the North Portugal Regional Operational Programme (NORTE 2020), under the PORTUGAL 2020 Partnership Agreement, and through the European Regional Development Fund (ERDF).

Open Access This article is distributed under the terms of the Creative Commons Attribution 4.0 International License (http://creativecommons.org/licenses/by/4.0/), which permits unrestricted use, distribution, and reproduction in any medium, provided you give appropriate credit to the original author(s) and the source, provide a link to the Creative Commons license, and indicate if changes were made.

\section{References}

[1] J. S. Sirkis, D. D. Brennan, M. A. Putman, T. A. Berkoff, A. D. Kersey, and E. J. Friebele, "In-line fiber etalon for strain-measurement," Optics Letters, 1993, 18(22): 1973-1975.

[2] Q. Rong, H. Sun, X. Qiao, J. Zhang, M. Hu, and Z. Feng, "A miniature fiber-optic temperature sensor based on a Fabry-Perot interferometer," Journal of Optics, 2012, 045002(14): 059501-059501.

[3] Q. Zhang, T. Zhu, Y. Hou, and K. S. Chiang, "All-fiber vibration sensor based on a Fabry-Perot interferometer and a microstructure beam," Journal of the Optical Society of America B, 2013, 30(5): 1211-1215.

[4] G. Z. Xiao, A. Adnet, Z. Zhang, F. G. Sun, and C. P. Grover, "Monitoring changes in the refractive index of gases by means of a fiber optic Fabry-Perot interferometer sensor," Sensors and Actuators A: Physical, 2005, 118(2): 177-182.

[5] M. S. Ferreira, L. Coelho, K. Schuster, J. Kobelke, J. L. Santos, and O. Frazão, "Fabry-Perot cavity based on a diaphragm-free hollow-core silica tube," Optics Letters, 2011, 36(20): 4029-4031.

[6] H. Gong, H. Song, X. Li, J. Wang, and X. Dong, “An optical fiber curvature sensor based on photonic crystal fiber modal interferometer," Sensors and 
Actuators A: Physical, 2013, 195(6): 139-141.

[7] M. Cano-Contreras, A. D. Guzman-Chavez, R. I. Mata-Chavez, E. Vargas-Rodriguez, D. JaureguiVazquez, D. Claudio-Gonzalez, et al., "All-fiber curvature sensor based on an abrupt tapered fiber and a Fabry-Pérot interferometer," IEEE Photonics Technology Letters., 2014, 26(22): 2213-2216.

[8] C. S. Shin and M. W. Lin, "An optical fiber-based curvature sensor for endodontic files inside a tooth root canal," IEEE Sensors Journal, 2010, 10(6):
1061-1065.

[9] M. S. Ferreira, P. Roriz, J. Bierlich, J. Kobelke, K. Wondraczek, C. Aichele, et al., "Fabry-Perot cavity based on silica tube for strain sensing at high temperatures," Optics Express, 2015, 23(12): 16063-16070.

[10] M. S. Ferreira, K. Schuster, J. Kobelke, J. L. Santos, and O. Frazão, "Spatial optical filter sensor based on hollow-core silica tube," Optics Letters, 2012, 37(5): 890-892. 